Chapman University

Chapman University Digital Commons

$12-11-2018$

\title{
Spreading the Good News: Analyzing Socially Shared Inspirational News Content
}

Qiaho Ji

Arthur A. Raney

Sophie Janicke-Bowles

Katherine R. Dale

Mary Beth Oliver

See next page for additional authors

Follow this and additional works at: https://digitalcommons.chapman.edu/comm_articles

Part of the Journalism Studies Commons, Mass Communication Commons, Other Communication Commons, and the Social Media Commons 


\section{Authors}

Qiaho Ji, Arthur A. Raney, Sophie Janicke-Bowles, Katherine R. Dale, Mary Beth Oliver, Abigail Reed, Jonmichael Seibert, and Arthur A. Raney II 
RUNNING HEAD: Inspirational News Sharing

Spreading the Good News: Analyzing Socially Shared Inspirational News Content

by

Qiaho Ji ${ }^{1}$, Arthur A. Raney ${ }^{2}$, Sophie H. Janicke ${ }^{3}$, Katherine R. Dale ${ }^{2}$, Mary Beth Oliver ${ }^{4}$, Abigail Reed ${ }^{2}$, Jonmichael Seibert ${ }^{2}$, and Arthur A. Raney, II $^{5}$

\footnotetext{
${ }^{1}$ Marist College

${ }^{2}$ Florida State University

${ }^{3}$ Chapman University

${ }^{4}$ Pennsylvania State University

${ }^{5}$ University of Alabama
}

Manuscript submitted for publication consideration to Journalism and Mass Communication

Quarterly, June 2017 


\begin{abstract}
Sharing news stories online is an increasingly common activity. Past research has identified the capacity to evoke positive emotions — especially awe — as an important content feature for news virality. However, to date, little attention has been paid to what makes news “awe-inspiring." In this study, we examined news articles shared over a 6-month period through The New York Times website to investigate how content features might predict the likelihood of an article being considered inspirational and being frequently shared. To do so, we developed and validated an Inspiring Media Content Dictionary (IMCD) to specifically analyze language associated with self-transcendent emotions. Our computational-manual hybrid coding method revealed that the use of words associated with self-transcendent emotions and emotional positivity significantly predicted inspirationality. Representations and language use associated with hope and an appreciation of beauty and excellence were particular common. Inspirational words also predicted the longevity of an article appearing on a most-shared list. Theoretical and practical implications are discussed.
\end{abstract}

Keywords: inspiring media, self-transcendent media, self-transcendent emotions, news, news sharing, virality, content analysis 


\section{Spreading the Good News: Analyzing Socially Shared Inspirational News Content}

The online sharing of news content—real or fake — is increasingly common.

According to the Reuters Institute for the Study of Journalism, one-quarter (25\%) of all American adults reported sharing a news story through a social media site in 2016, up from $21 \%$ the previous year; across Western Europe - particularly in Spain (34\%) and Italy (31\%) - that proportion is closer to one-third (Newman, Fletcher, Levy, \& Nielsen, 2017). Of course, social media sites are just one means of socially (re)transmitting stories, with e-mail, SMS, and various chat apps like WhatsApp also popular news-sharing platforms. Given these trends, it is unsurprising that scholars have started to investigate the characteristics associated with the news content that is typically shared and the people who typically share it (for a recent summary, see Kümpel, Karnowski, \& Keyling, 2015).

Several of these studies have identified emotional arousal as an important content factor in shared messages (e.g., Berger 2011; Dobele et al., 2007; Kim, 2015). Specifically, stories that can elicit highly arousing emotions tend to be retransmitted more often than those that cannot. Moreover, news stories that can evoke the highly arousing, positive emotion of awe have been found to be particularly share-worthy (e.g., Berger \& Milkman, 2012;

Heimbach \& Hinz, 2016). However, to date, little attention has been paid to the specific nature of and representations present in awe-inspiring news articles that are socially shared. Therefore, guided by previous work in the area, we conducted the first systematic content analysis of such news stories, examining articles shared through the New York Times website during a 6-month period.

\section{Emotions and News Sharing}

Berger (2011) first demonstrated the importance of highly arousing emotions in the social transmission of media messages. He found that people who had viewed highly arousing (i.e., amusement- and anxiety-inducing) film clips subsequently reported greater 
intention to share an unrelated article and video than those viewing low-arousing (i.e., contentment- and sadness-inducing) clips. Similarly, persons who lightly jogged in place for 60 seconds - thereby experiencing increased physiological arousal-were later more likely to e-mail a news article than those who remained stationary.

Building on this work, Berger and Milkman (2012) explored the emotionality of media content itself, with the expectation that emotion-evoking news articles-especially those evoking positive emotions - would increase reader arousal and lead to increased sharing (i.e., the article would become viral). The researchers examined a random sample of articles appearing on the home page of the New York Times, $20 \%$ of which also appeared on the Times most-emailed list (i.e., they went viral). Computer coding provided a sentiment analysis (i.e., positive and negative emotionality) of the articles, while human coders rated each along the emotional dimensions of awe, anger, anxiety, sadness, as well as surprise, practical utility, and interest. As the researchers expected, (especially positive) emotionality predicted virality. Further, among the emotional dimensions, ratings of awe were the strongest predictor of social sharing. Heimbach and Hinz (2016) reported a similar pattern of results when replicating the Berger and Milkman (2012) approach with a sample of German news articles. Thus, articles that can induce awe appear to be often shared, but we know little about the actual content found in such articles.

We contend that exploring the subject matter of and portrayals found in awe-inspiring news content is vital for researchers to better understand the potential benefits of exposure to such stories. Recently, media researchers began examining a broad class of content that includes such news stories: inspiring (or self-transcendent) media ${ }^{1}$ (e.g., Authors, 2017a; Rieger et al., 2015; Tsay-Vogel \& Krakowiak, 2016). This content is particularly important

\footnotetext{
1 These two terms are used synonymously herein. We contend that "inspiring media" is the more familiar term, while "self-transcendent media" is the more scientifically accurate (see Author, 2017a) though less familiar term referring to the same content.
} 
and socially relevant because of its potential to promote empathy, virtue, human connectedness, and prosociality (Author, 2012; Algoe \& Haidt, 2009; Haidt, 2003; Prestin, 2013; Schnall, Roper \& Fessler, 2010; Peterson \& Seligman, 2004). Stated another way, inspiring media messages — such as awe-inspiring news stories — can contribute to the development of trait transcendence.

\section{Transcendence and News Sharing}

Transcendence is the dispositional trait to strive for and connect with purpose and meaning greater or higher than ourselves; it is thought to be one of six core human virtues found in all cultures (Peterson \& Seligman, 2004). Individuals can develop trait transcendence by performing, and witnessing others perform behaviors associated with gratitude, hope, spirituality, and an appreciation for moral and physical beauty and excellence. Transcendence can also be developed, by experiencing related self-transcendent emotions, including awe (among others) (e.g., Algoe \& Haidt, 2009; Fredrickson, 2009; Haidt \& Morris, 2009). Thus, when people read awe-inspiring news stories, they can potentially develop and promote their own trait transcendence. Moreover, given the outward-orientation of transcendence, the sharing of awe-inspiring articles with others via social media sites or email is, in itself, another way to promote the development of the trait (in that, the sharing of information for another's benefit can reasonably be considered a prosocial and altruistic act).

As noted above, past research has established that articles that inspire awe are often socially retransmitted. Moral psychologists describe awe as the amazement elicited by vast, beautiful, or perfect stimuli (and the description thereof), which require a measure of accommodation because our capacity to understand and comprehend the experience is challenged (Keltner \& Haidt, 2003). Awe-inspiring news articles are those that evoke such feelings. In fact, this conceptualization of awe is precisely the one used by Berger and 
Milkman (2012; Web Appendix for the article), as well as Heimbach and Hinz (2016), to train coders in their earlier studies.

However, awe as a self-transcendent emotional response is quite similar to several others, specifically, elevation, admiration, gratitude, and hope. Elevation is often described as an uplifting, moving, and warm emotional experience in response to moral beauty and humanity's better nature, such as gratitude, charity, loyalty/fidelity, and generosity (Algoe \& Haidt, 2009; Diessner, Iyer, Smith \& Haidt, 2013; Haidt, 2003; Keltner \& Haidt, 2003). Admiration is the motivation and energy we feel when we encounter non-moral excellence, extraordinary skill, talent, or achievement (Algoe \& Haidt, 2009). Gratitude is characterized by the sense of wonder, thankfulness, and appreciation for life in response to, more generally, the positive things in life, or, more specifically, someone doing something for you (Wood, Froh, \& Geraghty, 2010). Hope is the belief that things can change for the better, whether in our own lives, in the lives of others, or for the world (Frederickson, 2009). A small set of laboratory experiments have demonstrated that these other self-transcendent emotions can also be triggered by elicitors found in media content (e.g., Author, 2012; Lai, Haidt, \& Nosek, 2014; Prestin, 2013; Schnall, Roper, \& Fessler, 2010; Van Cappellen, et al., 2013).

What binds all of these emotional experiences together under the banner of "self-transcendent" is the fact that they share a common type of elicitor: goodness or virtue found outside of ourselves, often in other people and their actions. Therefore, co-activation of several self-transcendent emotions is likely in response to the same media content; as a result, we contend that a holistic approach to examining self-transcendent media — as opposed to the more narrowly defined awe-inspiring media or news - is most appropriate. Further, doing so is socially significant because of the potential positive effects from exposure.

Scholarship in positive psychology explains how the experience of self-transcendent emotions can build our personal resources, leading us to explore and engage with our 
environment (i.e., the broaden-and-build theory; Fredrickson, 2001; 2009). As a result, we are drawn out of ourselves, our perspectives are broadened, and our attention and actions turns toward others. As noted above, a small-but-growing body of literature has demonstrated how media may facilitate the process; to this point, though, little of that research has examined news.

Given the potential personal and social benefits of consuming awe- and other self-transcendent emotion-inspiring news, and given the reported frequency with which such news is socially shared, we think the content warrants a more in-depth examination. To that end, we conducted the first systematic analysis of inspiring news content, adopting and expanding upon the protocols employed by Berger and Milkman (2012) and Heimbach and Hinz (2016). More specifically, we utilized computational and manual approaches to analyze a sample of articles appearing in the most emailed, most tweeted (on Twitter), and most Facebook posted articles from The New York Times website over a 6-month period.

Although Berger and Milkman's (2012) seminal work on awe-inspiring news sharing is foundational to our study, as previously noted, we contend that a more inclusive approach (i.e., beyond awe) is necessary to more appropriately reflect the broader concerns and current work of media researchers relative to inspiring or self-transcendent media. Thus, our study was motivated by three research questions dealing with more broadly conceptualized inspiring (i.e., not solely awe-inspiring) news. First, we asked,

RQ1: What type of content is contained in news articles that are considered inspirational?

To interrogate this question, we knew that new methodological tools would be needed. Because printed news stories must rely heavily — and, in most cases, solely — upon language to convey meaning, and because language can impart social and psychological constructs such as emotionality, social relationships, and social hierarchy important to the reception 
process (Tausczik \& Pennebaker, 2010), we focused our attention on the use of specific words that might elicit a self-transcendent emotion in a reader. To do so, we developed and applied an Inspiring Media Content Dictionary (IMCD) to systematically detect the presence of 370 English words, word stems, and phrases corresponding to six self-transcendent emotional experiences.

We suspected that inspirational news articles would feature more words associated with self-transcendent emotions than non-inspirational stories. We also expected, as previous research has suggested, that such stories would more likely contain terms associated with emotional positivity than non-inspirational news. Nevertheless, given the exploratory nature of this study, we decided to investigate these and related relationships through a second research question:

RQ2: What content features might predict an article to be considered inspirational?

Finally, emotional dimensions like awe, as well as other content features - practical utility, surprise, interest, and exemplification — have been associated with an increased frequency in retransmission (Berger \& Milkman, 2012; Kim, 2015). We thought that incorporating these and other content factors into our analyses might help to illuminate connections between inspirational news and virality. Therefore, we asked:

RQ3: What content features predict the virality of news considered inspirational?

\section{Method}

Guided by past research on news sharing and virality, we systematically analyzed articles that had been frequently retransmitted through the New York Times website (http://nytimes.com) during two 3-month periods (February-April and August-October 2016). A hybrid method of computational and manual content analysis was used to analyze the data (see Lewis, Zamith, \& Hermida, 2013).

\section{Sample}


Data were collected using a project-developed web crawler that utilized the New York Times API to systematically scrape the Top 20 most emailed, most tweeted (on Twitter), and most posted to Facebook lists every six hours (i.e., four times a day). The web crawler captured each article's title, author, publication date, section, rank on the corresponding list (1-20), URL, summary, and full text. During our sampling period, a total of 44,306 articles were captured. As one might expect, a large number of articles appeared multiple times within each of the three datasets due to their popularity over time (and because we collected the lists at such a high frequency). For instance, the Times' most read article of 2016-Alain de Botton's "Why You Will Marry the Wrong Person"- appeared 84 times in our Facebook list alone. Thus, deduplication of the data was necessary. This procedure yielded a total of 6,159 unique articles: 2,510 from the most emailed list, 1,804 from the most tweeted list, and 1,845 from the most shared on Facebook list. We retained the most recent/last ranked version of each article for our analysis. A small number of articles $(n=114)$ were not coded due to data collection and assignment errors. The final sample $(n=6,045)$ was subject to human coding and analyses, with a slightly smaller sample $(n=5,828)$ computer coded and analyzed because the API failed to return the full text to the dataset (though we were able to access the full text through the unique URLs for human coding).

\section{Coding Strategy}

The unit of analysis was the full text of each article. The Linguistic Inquiry and Word Count 2015 (LIWC 2015; Pennebaker, Boyd, Jordan, \& Blackburn, 2015) software was used for computerized coding of the deduplicated articles $(n=5,828)$. An advantage of LIWC 2015 over other textual analysis programs (in addition to its use in past studies on news virality) is the functionality of users uploading their own dictionary for strategic analytic purposes (see below). By default, LIWC 2015 measures variables by percentage. Because the average word count of the 5,828 articles was $1245.23(\mathrm{SD}=823.44)$, we report (where 
appropriate) the default percentage format (over an actual word count) to avoid bias based on varying article lengths.

Following Berger and Milkman (2012), we recorded total word count for each article and article complexity (i.e., words longer than six letters). To remain consistent with past research, we also computed an overall emotionality and emotional positivity score for each article (via LIWC's built-in sentiment analysis feature), based on the percentage sum of positive and negative words and the percentage difference between positive and negative words respectively.

Furthermore, we developed a dictionary of terms related to trait transcendence and self-transcendent emotions to be used by the analysis software to process the linguistic data (for a full description of this process, see Authors, 2017b). To do this, we followed expansive and contractive step-wise procedures similar to those used to develop the LIWC 2015 Dictionary (Pennebaker, Boyd, Jordan, \& Blackburn, 2015) and the Moral Foundation Dictionary (Graham, Haidt, \& Nosek, 2009). Specifically, in the first step, one author identified words, word stems, phrases, associations, and synonyms within six categories: five self-transcendent emotions (awe, admiration, elevation, hope, and gratitude) and a general emotional state of inspiration. Sources for the first-step procedure included official English dictionaries, online sources (e.g., transcripts of TED talks), and open-ended responses to items from past inspirational media surveys (Authors, 2017c; Authors, 2017d). Step 1 resulted in 755 full words, word stems, and multi-words phrases (e.g., profound, inspir*, look forward, etc.). An additional 28 words/word stems were generated via a brain-storming session involving the project research team. In Step 2, the authors examined each word in the dictionary in terms of their "fitness" for each category. In order for a word to remain in a given list, a majority of researchers had to agree on its inclusion. In case of disputes, we 
followed Pennebaker and colleagues' (2015) instruction and looked up online sources to determine a word's typical meaning and use. This procedure eliminated 141 words.

In Step 3, to ensure the validity of the dictionary, we checked the base rate of word usage in more than 1,250 TED talk transcripts, 35 music, art, science, and technology books from Project Gutenberg, more than 200,000 tweets collected for other research purposes over the course of three years, and the February data from our own sample (Pennebaker, et al., 2015). We removed from the dictionary all words that appeared zero times across all of those sources and further scrutinized words that appeared fewer than 10 times. The resulting Inspirational Media Content Dictionary (IMCD) ${ }^{2}$ included a total of 370 words, word stems, and phrases within six categories: awe, admiration, elevation, hope, gratitude, and general inspiration. Due to the overlapping nature of these experiences, some terms appeared within multiple categories (e.g., grat* appears in the list for awe, admiration, elevation, and gratitude; appreciate* appears in the list for both gratitude and admiration). After uploading the IMCD to the LIWC platform, we measured the frequency of words related to awe, admiration, elevation, hope, gratitude, and general inspiration. An overall inspirational word use factor was also created for each article by summing these six measures (after removing cross-categorized words).

In addition to the computerized coding, news articles were subject to human coding on 10 dimensions (discussed below). One senior researcher and two trained graduate student coders (who were blind to the specific nature of the project) were involved in the human coding process. A random sample of $10 \%$ of the articles from each dataset was extracted for practice coding and to establish intercoder reliability. During a series of practice coding sessions, preliminary results were discussed and disputes reconciled. Final intercoder

\footnotetext{
${ }^{2}$ A printed version of the IMCD is available here: [URL blinded for review].
} 
reliability estimates ranged from Krippendorf's $\alpha=.74$ to .91 . Given sufficient reliability, each coder then assessed one third of the full sample along the 10 dimensions.

First, each article was judged to be inspirational or not $(0=$ no; $1=$ yes $)$. Specifically, following Berger and Milkman's general approach, coders were provided with definitions of the five self-transcendent emotions of interest (awe, admiration, elevation, gratitude, and hope). ${ }^{3}$ Coders then read the full text of each story. Articles were rated as inspirational if they elicited any of the five self-transcendent emotions. This particular variable yielded the highest inter-coder reliability (Krippendorf's $\alpha=.91$ ). We next identified the inspirational nature of the inspirational articles (only) based on a typology adapted from Authors (2017d). Specifically, coders categorized the general content of the story as pertaining to: (1) family, relationships, and partnerships, (2) altruism/philanthropy toward non-family, (3) animals, (4) disaster or tragedy, (5) personal achievements or struggles, (6) political or social issues (including crime), (7) science, technology, health, or medical discoveries, (8) arts, music, and entertainment, (9) sports, (10) religion or spirituality, (11) other, or (12) mixed.

Coders next evaluated the "main characters" presented in each inspirational story, recording gender, occupation, and ethnicity (when discernible). Also, following procedures described by Authors (2017c), we coded whether or not $(0=$ no; $1=$ yes $)$ the main characters in the story displayed the behaviors/character strengths associated with trait transcendence discussed earlier: appreciation of beauty and excellence (e.g., praising another's accomplishments, displaying an extraordinary skill or talent, encountering art, nature, or architecture), gratitude (e.g., giving or receiving gifts, showing kindness), hope (e.g., overcoming obstacles, offering encouragement), and religiousness/spirituality (e.g., participating in religious rituals, wearing spiritual symbols).

\footnotetext{
3 This approach differs from Berger and Milkman (2012), who had coders rate the level of awe (only) on a scale of 1 (not at all) to 5 (extremely). Given the expanded nature (i.e., beyond awe) of our research such a methodological change was necessary. Further, given the overlapping relationships between the various self-transcendent emotions, the decision to evaluate presence/absence of any one emotion versus more subjective ratings of the relative level of each emotion was warranted for the sake of parsimony and validity.
} 
Following Berger and Milkman (2012), we also coded the level of practical utility, surprise, and interest of all articles using a 5-point scale ( 1 = "not at all;" 5 = "extremely"). Additionally, following Kim (2015), coders identified ( 0 = absent; $1=$ present $)$ whether the article contained exemplification (i.e., inclusion of personal stories or experiences of people related to the news topic). Articles were also coded as hard or soft news ( $0=$ soft; $1=$ hard $)$ based on the general topic covered (Horan, 2013).

Finally, we calculated three measures of virality for each article based on information gathered by the web crawler. First, we computed the number of times each article appeared on each list during the sampling frame (regardless of rank), with higher values indicating an article appeared more often. Because this value necessarily reflects a measurement of temporality, we refer to this as our longevity measure of virality. We also collected the highest rank each article achieved on each list (highest rank), as well as the number of lists (1-3) on which each article appeared, representing the number of different sharing platforms (platform diversity). ${ }^{4}$

\section{Results}

The first goal of this project was to gain a thorough understanding of the content features associated with inspirational stories (RQ1). Of the 6,045 articles coded, $21.1 \%(n=$ $1,275)$ were judged to be inspirational. Figure 1 depicts the distribution of inspirational and non-inspirational stories over time. The greatest number of inspirational stories appearing on any list was on February $23(n=22)$; the fewest appeared on March $14(n=0)$. Across our entire sampling frame, the frequency of inspirational and non-inspirational stories was

\footnotetext{
${ }^{4}$ One could argue that "total number of times each article was shared" is the ideal measure of virality. We do not disagree. However, at the time of data collection, we were unable to extract that information using the New York Times API. Therefore, as past researchers have done, we adopted proxy measures to reflect different dimensions of news virality. Granted, each measure has it shortcomings (see the related discussion in the Web Appendix in Berger and Milkman [2012]). Nevertheless, we contend that our triangulated approach to measuring virality is (a) in keeping with past research, and (b) quite valuable, informative, systematic, and valid.
} 
significantly correlated $(r=.312, p<.001)$; however, during a few time periods (e.g., the end of April, the month of September), inspirational stories appeared relatively less frequently. Insert Figure 1 here-

Table 1 reports the results of a series of t-tests comparing the content characteristics found in inspirational and non-inspirational stories. In line with our expectations, inspirational articles featured significantly higher percentages of positive emotional words, total inspirational words, as well as words associated with all six categories in the IMCD. The ten IMCD terms appearing the most frequently in the inspirational articles were help* $(n=$ 781), lov* $(n=588)$, learn* $(n=395)$, grow* $(n=381)$, power* $(n=376)$, belie* $(n=351)$, kind* $^{*}(n=366)$, great $(n=347)$, hope* $(n=276)$, and interest* $(n=263)$. Further, inspirational stories were rated to be significantly higher in terms of interest, surprise, and practical utility. Non-inspirational articles featured a significantly greater percentage of negative words and more emotional words overall (due to the high frequency of terms associated with negative emotions).

\section{-Insert Table 1 here}

In terms of the content contained in inspirational articles, stories reporting political and social issues $(22.1 \%)$, personal achievement (20.8\%), science, health, technology, and medical-related discoveries (19.8\%), arts, entertainment, and music-related topics (13.6\%), and sport $(8.8 \%)$ were most common. For the transcendence-related character strengths, more than half (61.8\%) of the inspirational articles described some form of appreciation of beauty and excellence, $42.5 \%$ reported a character enacting hope, and $30.1 \%$ of articles described gratitude. Only $3.5 \%$ of inspiring stories contained descriptions of behaviors associated with religiousness or spirituality.

As one might expect with such texts (which contained no pictures), the gender, ethnicity, and occupations of the leading characters were not always evident; for the 
inspirational articles, the gender of the lead character was discernible in $50.8 \%$ of the cases, the race of the main characters in $44.5 \%$, and the occupation of the lead character in $68.2 \%$. For the inspirational stories in which the leading characters were sufficiently described or identified, males $(67.2 \%)$ were featured more than twice as often as females $(30.8 \%)$. Inspirational articles featuring Whites were most common (58.7\%), followed by stories featuring African Americans (21.9\%), Asians (7.3\%), and persons from the Middle East $(6.3 \%)$. With regard to occupations, stories featuring scientists and educators $(15.6 \%)$ were most common, followed by those featuring artists $(14.6 \%)$, athletes $(12.7 \%)$, celebrities (11.0\%), and "ordinary people"/citizens (10.7\%).

We also examined the content characteristics that might predict an article being considered inspirational (RQ2). Because the dependent variable was categorical in nature (i.e. inspirational or not), multinomial logistic regression was used to interrogate the research question, with the percentage of emotionally positive and overall emotional words initially regressed on inspirationality (Table 2, Step 1). Results indicated that both factors were significant predictors of an article being considered inspirational, though overall emotionality did so negatively (again, likely because the high frequency of terms associated with negative emotions found in the non-inspiring articles).

The six categories from the IMCD were next entered into the model (Table 2, Step 2). The percentage of general inspirational, admiration, elevation, and hope related words significantly predicted whether an article was considered inspirational; these relationships (except for admiration) remained robust after controlling for many other content characteristics (Table 2, Step 3). The proportion of awe-related terms approached significance. Words associated with gratitude were not found to predict inspirationality; in fact, when other content factors were statistically controlled, gratitude words became a significant negative predictor of inspirationality. Over and above the predictive power of the 
emotional language used, several other content factors predicted an article being judged to be inspiring (in order of strength): presence of exemplification, interest rating, being a soft news story, practical utility, word count, and language complexity (negatively).

\section{-Insert Table 2 here}

Finally, linear regression models were estimated using the ordinary least squares method to examine the relationship between content characteristics and the virality of inspiring news articles (RQ3). The three measures of virality — longevity, highest rank, and platform diversity - were regressed on the content characteristics and control variables used to examine RQ2. No discernible pattern of influence was revealed for the inspirational articles, with only word count being a significant predictor across all three measures of virality (Longevity: $B=2.20,95 \%$ CI $[1.59,2.80]$; Rank: $B=1.02,95 \%$ CI $[.68,1.36]$; Diversity: $B=.01,95 \%$ CI $[.01, .11])$. Additionally, interest and surprise predicted platform diversity $\left(B_{\text {Interest }}=-.09,95 \%\right.$ CI $[-.16,-.02] ; B_{\text {Surprise }}=.17,95 \%$ CI $\left.[.11, .23]\right)$ of shared inspirational stories, while practical utility predicted the highest ranking achieved by an inspirational article on any list $(B=.40,95 \% \mathrm{CI}[.02, .77])$.

To further explore these issues, we entered the virality of all news articles (i.e., inspiring and non-inspiring) as dependent variables. As Table 3 indicates, word count again was the only predictor across all three measures of virality (Longevity: $B=1.17,95 \%[.91$, 1.43]; Rank: $B=.66,1095 \%$ CI $[.48, .83]$; Diversity: $B=.08,95 \%$ CI $[.05, .11])$; in fact, it was the only significant predictor of highest rank. Further, of particular note for our purposes, the percentage of total inspirational words $(B=.39,95 \%$ CI $[.12, .66])$ was the second strongest predictor (following word count) of longevity, which was also predicted by emotionality $(B=.18,95 \%$ CI $[.02, .35])$, practical utility $(B=.36,95 \%$ CI $[.08, .64])$, and (negatively by) interest ( $B=-.34,95 \%$ CI [-.66, -.02]). Platform diversity as a measure of virality was most strongly predicted by the proportion of emotional words $(B=.06,95 \% \mathrm{CI}$ 
$[.04, .07])$, followed by surprise $(B=.09,95 \% \mathrm{CI}[.06, .11])$, word count, and exemplification $(B=.07,95 \%$ CI $[.02, .12])$; positive words $(B=-.03,95 \%$ CI $[-.04,-.01])$ and interest $(B=$ $-.07,95 \% \mathrm{CI}[.06, .11])$ both negatively predicted platform diversity. -Insert Table 3 here

\section{Discussion}

Past research has repeatedly identified "awe-inspiring" as a characteristic of frequently shared (or viral) news, but to date no studies have actually examined the content of such stories. To address this gap, we examined a 6-month sample of (more broadly defined) inspirational stories shared via email, Twitter, and Facebook through the New York Times website. In addition to relying on techniques used in the past studies, we developed and validated a new methodological tool called the Inspirational Media Content Dictionary (IMCD), which identified words related to self-transcendent emotions (including awe) appearing in the stories in our sample.

Our findings revealed that more than one in five of the most socially shared articles through the Times website were inspirational in nature. Given that our data were collected during the primary season of a highly contentious election year, this proportion might be somewhat conservative relative to years in which less political coverage might be found (Berger, 2016). Nevertheless, this finding suggests that inspirational news stories are rather popular in our social lives. Across time, the ratio of inspiring-to-non-inspiring stories shared was fairly consistent, though some variation did seem to exist. Future studies might consider how current events and issues impact the frequency at which inspirational stories are shared. Do tragedies or crises in the world supersede and "drown out" the sharing of positive messages? Or do they promote an increase in sharing of positive messages as a way, for instance, for readers to cope? If the latter, are particular types of stories more likely to be 
shared contemporaneous with or soon after particular types of news events? More exploration of these issues seems warranted.

In terms of the specific content, inspiring news stories were more likely than non-inspiring stories to contain words associated with all five self-transcendent emotions and general inspiration, emotionally positive words, as well as to be judged as useful, interesting, and surprising. They also tended to contain more words in general. In contrast, non-inspirational articles actually featured more total emotional-oriented words (clearly due to the presence of more negatively valenced terms). The general findings related to emotionality are consistent with past research: articles stirring emotions, especially positive emotions, are share-worthy (see more on virality below). One unique contribution of the current study, though, was the development and implementation of a linguistic tool to identify terms associated with self-transcendent emotions. The Inspirational Media Content Dictionary (IMCD) allowed us to explore the phenomenon with much greater precision than past work, which identified "awe-inspiring" as a general descriptor of frequently retransmitted news. In fact, we found that terms conceptually related to awe were actually less frequent (at least descriptively speaking) than those associated with several other self-transcendent emotions (hope, admiration, and gratitude). We contend that this finding provides additional justification for expanding work in this area beyond awe to all forms of self-transcendent emotions. As noted above, a small group of media (primarily entertainment) scholars have begun exploring the more broadly conceptualized content area known as self-transcendent media. We think the findings of the current study provide a rationale for extending that conceptualization to the area of news and news sharing (and beyond the more narrowly defined category of awe-inspiring). We further contend that the IMCD can be a powerful tool for those interested in doing so. 
Inspirational stories were more likely to center on political/social issues, personal achievement, discoveries in science, health, technology, and medicine, and the arts. Lead characters in inspirational stories reflected longstanding trends (or biases) in media coverage: an overrepresentation of Whites and males (Mastro, 2009). With regard to the occupation of lead characters in inspirational stories, scientists and educators were most common, which is consistent with the high percentage of science-discovery stories found in the sample. This particular findings put the first "face" on inspiring news. Perhaps unexpectedly (particularly given the readership makeup of the Times) that face reflects mainstream America. The question remains whether this face is merely a reflection or function of overall representations in news, if inspirational stories actually differ from non-inspirational ones in terms of these representations, or if readers gravitate to or are inspired by stories about people who are more similar to themselves. More research is needed to explore these issues.

With regard to themes associated with trait transcendence found in the articles, inspiring stories were more likely to contain representations reflecting an appreciation of beauty and excellence and hope (as opposed to gratitude and spirituality/religiousness). Conceptually speaking, elicitors of awe (e.g., vastness in nature and space) are closely aligned with the appreciation of beauty and excellence in the positive psychology literature. Thus, this finding is in line with the past news-sharing work that has highlighted awe-inspiring content. In addition, the hope-related behavioral representations are similar to the IMCD findings (see Table 1) in which hope-related words were the most frequent (at least descriptively speaking) among the self-transcendent emotional terms. Furthermore, the prevalence of hope-related depictions in the articles mirrors recent content analyses on inspiring content in YouTube videos (Authors, 2017c). Together, these findings offer additional brushstrokes to the emerging picture of inspiring media, namely the elevated importance of representations related to hope and an appreciation for moral and physical 
beauty and excellence. Continued work is encouraged to bring that picture into complete focus. But also of note are the findings related to gratitude (a negative predictor of inspirationality) and religiousness/spirituality (relatively absent from inspirational stories). We have no ready explanation for the former, while the later may be a reflection of either the lack of news about religion and spirituality or the lack of importance of (or inspiration found in) such coverage in the lives of readers.

Our study also revealed that the percentage of emotionally positive words used were significantly associated with an article being considered inspirational; the percentage of overall emotional words also predicted, but negatively, an article being considered inspirational. These findings held true when controlling for other language use and content characteristics. Furthermore, when we analyzed the use of inspirational words by the six sub-categories in the IMCD, we found that a 1 standard deviation increase in the use of words related to inspiration (general), elevation, and hope increased the odds that an article would be considered inspirational by .48 to .94 times (Table 2, Step 3). In contrast, and perhaps somewhat surprisingly, the use of words related to awe and admiration were not found to contribute to an article's inspirationality (after controlling for other content factors). Furthermore, terms associated with gratitude actually decreased the likelihood of an article being considered inspirational by $17 \%$.

At this point, we do not have a sound theoretical explanation for why terms associated with some of the self-transcendent emotions functioned differently in predicting the probability of an article being considered inspirational. One potential explanation could be tied to the historical effect of data collection. As noted, our sample was drawn during the contentious primary and general election season of an election year; we suspect that certain campaign-related articles (most of which were categorized as non-inspirational) might have used inspirational words in a non-traditional fashion, which obviously could have impacted 
our findings. In fact, a follow-up examination isolating articles featuring political leaders and governmental officials alone ( $n=1,883$; mostly coded as non-inspirational) suggested descriptively higher percentages of words related to all categories of inspirational words (except elevation) than those in the other non-inspirational articles (which focused on different topics and themes). This points to a larger issue about polysemy and language use in various contexts, issues that must be addressed as we continue this work.

Finally, in light of recent work on news virality, we tested possible predictors for news retransmission among those articles coded as inspirational and overall. Considering the lack of access to the actual number of times article being shared, three proxy measures for news virality were modeled as dependent variables. No clear pattern of results emerged for predicting the virality of inspirational stories, except for word count. Results suggested that the overall number of words used in a story consistently predicted the virality of an inspiring news article (as well as any article) across the three models; this is in accordance with findings in previous news virality research (Berger \& Milkman, 2012).

With regard to virality across all news stories in our sample, we found that the percentage of inspiring words (as measured by the IMCD) trailed only word count in its power to predict the longevity of an article's virality. Practically, this suggests that news articles containing more words related to self-transcendent emotions might increase any article's longevity of being shared among readers. Theoretically, this could matter a great deal, since exposure to inspirational media messages can promote psychological well-being, human flourishing, and prosociality. Furthermore, this finding builds on past research — which relied on subjective ratings of an article's awe-inspiring value — to identify and validate objective and quantifiable markers of the role of self-transcendent emotions in the virality of news. This finding should serve as a building block for future studies in which the full linguistic anatomy of inspiration is mapped. Additional content factors also impacted 
an article's virality (depending on the measure), including the proportion of positive words, overall use of emotional words, use of exemplification, as well as levels of practical utility, interest, and surprise. We encourage future studies that further investigate the complexity of inspirational news virality.

Despite the encouraging results reported herein, we acknowledge that this study is not without limitations. First, past news sharing research has found that additional variables - the gender and fame of the author, the story's location on the home page, to name a few-can also impact virality. Although we included quite a few variables in our study, we acknowledge that our final model only predicted a small proportion of the overall variance in virality. Even more complex models are needed to better understand the complexity of frequent news sharing. Second, as we noted, virality was indirectly gauged through three proxy measures (due to limits on the information available through the Times API). As we admitted, these measures are somewhat imperfect. For instance, the number of times of each article appeared on a list can be affected by publication time or date; articles published in February may be more likely to be shared as compared to one published in April simply because it was available to be shared for a longer period of time. Future studies must continue to wrestle with the best ways to conceptualize and measure virality. Third, because our study solely relied upon textual data, some information that might have been present through the webpage or in the print edition at the time of publication (e.g., an image or video) was not obtained or analyzed. We know from past research that those contents (e.g., a picture of the vastness of space, a video of a last-second goal) can inspire. Thus, because those elements are not present in our analysis (though they are possibly present to the reader at the time the article is shared), we may be underestimating the potential positive impacts of articles as they are typically encountered. Future studies are encouraged to attempt to also gather those message elements for examination. A final limitation arises from general 
concern with all LIWC analyses, which cannot account for contextual language cues such as satire and metaphor. We partially addressed this in our study by restricting our data to the New York Times (thus “controlling” for language style) and having a large sample size. Nonetheless, the use of other novel methods or tools for textual analyses (e.g., Google Cloud Natural Language API) are encouraged.

Ultimately, we think this study makes several contributions to our growing understanding of inspirational media content by providing a much more granular picture of the positive forms of news stories begin shared than has previously been offered. The role of "awe" in content that has previously been termed as "awe-inspiring" is possibly somewhat limited — or augmented — by the presence of other content features related to self-transcendent emotions and trait transcendence. These findings help us to begin to connect the dots between what we know to be inspiring in general (i.e., elicitors associated with transcendence, self-transcendent emotions) and how that may be communicated (especially textually) in media. The study further contributes to our growing understanding of viral media, especially viral news. And, from a methodological perspective, we think the construction of the IMCD can enable researchers to better explore inspiring media content in both print media and social network sites. Further, content creators might find the dictionary a useful tool in developing linguistic guidelines for crafting inspiring text-based messages. Ultimately, better understanding the complexity of inspiring news stories is important for communication and media scholars given the potential positive benefits to the psychological well-being of readers and, in turn, society. 


\section{References}

Authors, 2012.

Authors, 2016.

Authors, 2017a.

Authors, $2017 \mathrm{~b}$.

Authors, 2017c.

Authors, 2017d.

Algoe, S. B., \& Haidt, J. (2009). Witnessing excellence in action: The 'other-praising' emotions of elevation, gratitude, and admiration. Journal of Positive Psychology, 4, 105-27. doi: 10.1080/17439760802650519

Berger, J. (2011). Arousal increases social transmission of information. Psychological science, 22, 891-893. doi: 10.1177/0956797611413294

Berger, J. (2016). Contagious: Why things catch on. New York: Simon and Schuster.

Berger, J., \& Milkman, K. L., (2012). What makes online content viral? Journal of Marketing Research, 49, 192-205. doi: 10.1509/jmr.10.0353

Diessner, R., Iyer, R., Smith, M., M., \& Haidt, J. (2013). Who engages with moral beauty? Journal of Moral Education, 42, 139-163. doi: 10.1080/03057240.2013.785941

Dobele, A., Lindgreen, A., Beverland, M., Vanhamme, J., \& Van Wijk, R. (2007). Why pass on viral messages? Because they connect emotionally. Business Horizons, 50, 291-304. doi:10.1016/j.bushor.2007.01.004

Fredrickson, B. L. (2001). The role of positive emotions in positive psychology: The broaden-and-build theory of positive emotions. American Psychologist, 56, 218-226. doi:10.1037/0003-066X.56.3.218 
Fredrickson, B. L. (2004). Gratitude, like other positive emotions, broadens and builds. In R. A. Emmons \& M. E. McCullough (Eds.), The psychology of gratitude (pp. 145-166). New York, NY: Oxford University Press.

Fredrickson, B. L. (2009). Positivity. New York: Three Rivers Press.

Graham, J., Haidt, J., \& Nosek, B. A. (2009). Liberals and conservatives rely on different sets of moral foundations. Journal of Personality and Social Psychology, 96, 1029-1046. doi:10.1037/a0015141

Haidt, J. (2003). The moral emotions. In R. J. Davidson, K. R. Scherer, \& H. H. Goldsmith (Eds.), Handbook of affective sciences (pp. 852-870). Oxford, England: Oxford University Press.

Haidt, J., \& Morris, J. P. (2009). Finding the self in self-transcendent emotions. Proceedings of the National Academy of Sciences, 106, 7687-7688. doi:10.1073/pnas.0903076106

Heimbach, I., \& Hinz, O. (2016). The impact of content sentiment and emotionality on content virality. International Journal of Research in Marketing, 33, 695-701. doi:10.1016/j.ijresmar.2016.02.004

Horan, J. T. (2013). 'Soft' versus 'hard' news on microblogging networks. Information, Communication \& Society, 16, 43-60. doi: 10.1080/1369118X.2011.649774

Keltner, D., \& Haidt, J. (2003). Approaching awe: A moral, spiritual, and aesthetic emotion. Cognition \& Emotion, 17, 297-314. doi:10.1080/02699930302297

Kim, H. S. (2015). Attracting views and going viral: How message features and news sharing channels affect health news diffusion. Journal of Communication, 65, 512-534. doi:10.1111/jcom. 12160

Kümpel, A. S., Karnowski, V., \& Keyling, T. (2015). News sharing in social media: A review of current research on news sharing users, content, and networks. Social Media + Society, 1(2), 1-14. doi:10.1177/2056305115610141 
Lai, C. K., Haidt, J., \& Nosek, B., A. (2014). Moral elevation reduces prejudice against gay men. Cognition \& Emotion, 28, 781-794. doi:10.1080/02699931.2013.861342

Lai, C. K., Haidt, J., \& Nosek, B., A. (2014). Moral elevation reduces prejudice against gay men. Cognition \& Emotion, 28, 781-794. doi:10.1080/02699931.2013.861342

Lewis, S. C., Zamith, R., \& Hermida, A. (2013). Content analysis in an era of big data: A hybrid approach to computational and manual methods. Journal of Broadcasting \& Electronic Media, 57, 34-52. doi:10.1080/08838151.2012.76170

Mastro, D. (2009). Effects of racial and ethnic stereotyping. J. Bryant \& M .B. Oliver (Eds.), Media effects: Advances in theory and research (pp. 325-341). New York: Routledge.

Newman, N., Fletcher, R., Levy, D. A. L., \& Nielsen, R. K. (2017). Reuters Institute digital news report 2016. Reuters Institute for the Study of Journalism, University of Oxford. Retrieved from http://www.digitalnewsreport.org/

Pennebaker, J.W., Boyd, R.L., Jordan, K., \& Blackburn, K. (2015). The development and psychometric properties of LIWC2015. Austin, TX: University of Texas at Austin. doi:10.15781/T29G6Z

Peterson, C., \& Seligman, M. E. P. (2004). Character strengths and virtues: A handbook and classification. Washington, DC: American Psychological Association.

Rieger, D., Reinecke, L., Frischlich, L., \& Bente, G. (2014). Media entertainment and well-being linking hedonic and eudaimonic entertainment experience to media-induced recovery and vitality. Journal of Communication, 64, 456-478. doi:10.1111/jcom.12097

Schnall, S., Roper, J., \& Fessler, D. M. T. (2010). Elevation leads to altruistic behavior. Psychological Science, 21, 315-320. doi:10.1177/0956797609359882 
Tausczik, Y. R., \& Pennebaker, J. W. (2010). The psychological meaning of words: LIWC and computerized text analysis methods. Journal of Language and Social Psychology, 29, 24-54. doi: 10.1177/0261927X09351676

Tsay-Vogel, M. \& Krakowiak, K.M. (2016) Inspirational reality TV: The prosocial effects of lifestyle transforming reality programs on elevation and altruism. Journal of Broadcasting \& Electronic Media, 60, 567-586. doi:

$10.1080 / 08838151.2016 .1234474$

Van Cappellen, P., Saroglou, V., Iweins, C., Piovesana, M., \& Fredrickson, B., L. (2013). Self-transcendent positive emotions increase spirituality through basic world assumptions. Cognition and Emotion, 27, 1378-1394.

doi:10.1080/02699931.2013.787395

Wood, A. M, Froh, J. J., \& Geraghty, A. (2010). Gratitude and well-being: A review and theoretical Integration. Clinical Psychology Review, 30, 890-905. doi:10.1016/j.cpr.2010.03.005 


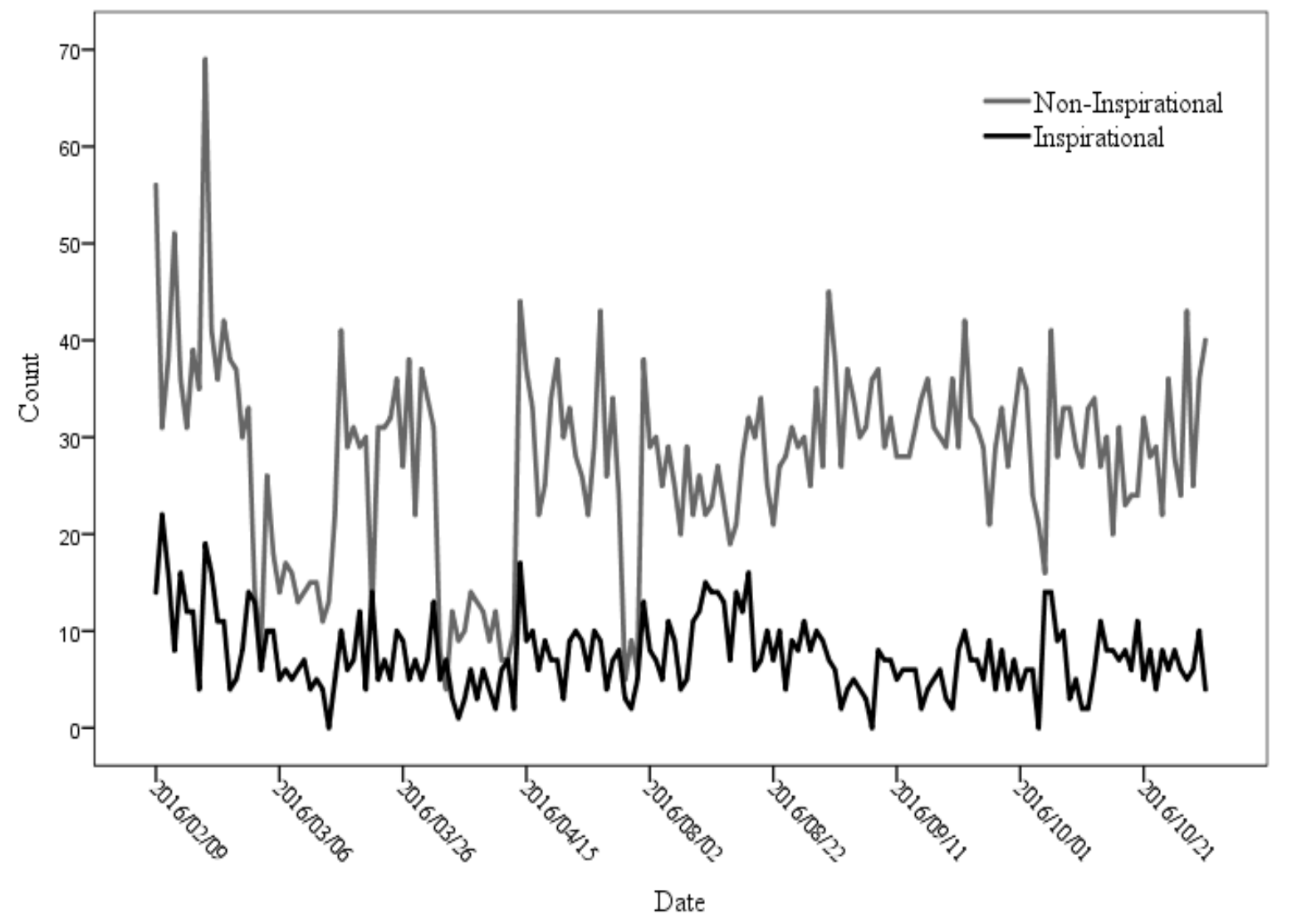

Figure 1. Frequency of inspirational and non-inspirational stories over sampling frame. 
Table 1. Differences between inspirational and non-inspirational article content

\begin{tabular}{lccc}
\hline & $\begin{array}{c}\text { Inspirational stories } \\
(n=1,275)\end{array}$ & $\begin{array}{c}\text { Non-inspirational stories } \\
(n=4,740)\end{array}$ & \\
\cline { 2 - 4 } Measure $^{\mathrm{a}}$ & $M(S D)$ & $M(S D)$ & $t^{\mathrm{b}}$ \\
\hline Overall emotionality $^{\text {Emotional positivity }}$ & $3.89(1.48)$ & $4.20(1.46)$ & -6.65 \\
Inspirational words total & $1.03(1.34)$ & $0.34(1.52)$ & 15.45 \\
Inspiration (general) words & $2.28(1.02)$ & $1.94(.92)$ & 11.03 \\
Awe words & $.43(.33)$ & $.35(.32)$ & 7.58 \\
Gratitude words & $.50(.43)$ & $.41(.42)$ & 6.43 \\
Elevation words & $.52(.41)$ & $.45(.38)$ & 5.24 \\
Admiration words & $.40(.30)$ & $.32(.26)$ & 8.52 \\
Hope words & $.68(.53)$ & $.56(.46)$ & 7.30 \\
Practical utility & $.77(.44)$ & $.69(.41)$ & 6.17 \\
Interest & $1.84(.86)$ & $1.67(.78)$ & 6.79 \\
Surprise & $3.12(.83)$ & $2.59(.76)$ & 20.80 \\
\hline Note: All values are & $2.68(.89)$ & $2.43(.97)$ & 8.30 \\
\hline
\end{tabular}

Note: ${ }^{\text {a }}$ All values are reported as percentages, except for practical utility, interest, and surprise (which were measured as integers, $1=$ "not at all", 5 = "extremely").

${ }^{\mathrm{b}}$ All t-tests were significant at $p<.001$ level 
Table 2. Predicting likelihood of article being considered inspirational

\begin{tabular}{|c|c|c|c|}
\hline & $\begin{array}{l}\text { Step 1: General } \\
\text { emotions }\end{array}$ & $\begin{array}{c}\text { Step 2: } \\
\text { Self-transcendent } \\
\text { emotions }\end{array}$ & $\begin{array}{l}\text { Step 3: Content } \\
\text { controls }\end{array}$ \\
\hline \multicolumn{4}{|l|}{ Step 1: General emotions } \\
\hline Overall emotionality & $-.19 * *(.02)$ & $-.32 * *(.11)$ & $-.30 * *(.03)$ \\
\hline Emotional positivity & $.36 * *(.03)$ & $.27 * *(.03)$ & $.21 * *(.03)$ \\
\hline \multicolumn{4}{|c|}{ Step 2: Self-transcendent emotions } \\
\hline General inspiration & & $.27 * *(.03)$ & $.70 * *(.11)$ \\
\hline Awe & & $.18^{\dagger}(.10)$ & $.028(.11)$ \\
\hline Admiration & & $.28^{*}(.10)$ & $.17(.11)$ \\
\hline Elevation & & $.80 * *(.13)$ & $.94 * *(.15)$ \\
\hline Gratitude & & $-.15(.10)$ & $-.17 *(.11)$ \\
\hline Hope & & $.26^{*}(.09)$ & $.48 *(.10)$ \\
\hline \multicolumn{4}{|l|}{ Step 3: Content controls } \\
\hline Practical utility & & & $.14 *(.06)$ \\
\hline Surprise & & & $.01(.04)$ \\
\hline Interest & & & $.60 * *(.05)$ \\
\hline Exemplification & & & $.89 * *(.08)$ \\
\hline Word Count $\times 10^{-3}$ & & & $.12 *(.04)$ \\
\hline Word Complexity & & & $-.04 *(.01)$ \\
\hline Hard/soft news & & & $-.55 * *(.08)$ \\
\hline Observations & 5,798 & 5,798 & 5,792 \\
\hline McFadden's $R^{2}$ & .046 & .067 & .175 \\
\hline
\end{tabular}

${ }^{\dagger} p<.1 * p<.05 ; * * p<.001$

Note: Cell entries are unstandardized regression coefficients with standard errors in parentheses. Missing data were handled with listwise deletion. Exemplification was coded "present" $=1$, "absent" $=0$. Word count was measured as an integer; it is reported $\times 10^{-3}$ to facilitate comparison and interpretation. Hard/soft news was coded "hard" = 1, "soft" = 0 . 
Table 3. Predicting overall news virality $(n=5,808)$

\begin{tabular}{|c|c|c|c|}
\hline & Longevity & Highest rank & Platform diversity \\
\hline \multicolumn{4}{|l|}{ Step 1: Emotions } \\
\hline Positivity & -.01 & .03 & $-.06^{*}$ \\
\hline Emotionality & $.04^{*}$ & .02 & $.14 * *$ \\
\hline Inspirational words & $.05^{*}$ & .02 & .02 \\
\hline \multicolumn{4}{|l|}{ Step 2: Content controls } \\
\hline Practical utility & $.03 *$ & .01 & -.02 \\
\hline Surprise & .00 & -.01 & $.10 * *$ \\
\hline Interest & $-.03 *$ & -.02 & $-.06 * *$ \\
\hline Exemplification & .03 & .03 & $.04 *$ \\
\hline Word Count $\times 10^{-3}$ & $.12 * *$ & $.10 * *$ & $.08 * *$ \\
\hline Complexity & .02 & .01 & -.00 \\
\hline Hard/soft news & -.02 & .06 & .00 \\
\hline$\overline{R^{2}}$ & .021 & .017 & .028 \\
\hline
\end{tabular}

$* \mathrm{p}<.05 ; * * \mathrm{p}<.001$

Note: Cell entries are standardized regression coefficient. Dependent variable was reverse coded for the models predicting highest ranks. VIFs were smaller than 1.80 for all models. Missing data were handled with listwise deletion. Exemplification was coded "present" $=1$, "absent" $=0$. Word count was measured as an integer; it is reported $\times 10^{-3}$ to facilitate comparison and interpretation. Hard/soft news was coded "hard" = 1, "soft" $=0$. 